\title{
Long term outcome after surgery for extrahepatic portal vein thrombosis
}

\author{
Paul D Losty, Michael J Lynch, Edward J Guiney
}

\begin{abstract}
The long term outcome of 21 children with extrahepatic portal hypertension secondary to portal vein thrombosis managed by surgical intervention was evaluated. Portosystemic shunts, used primarily in nine patients (eight central splenorenal, one mesocaval) after conservative treatment had failed, had no associated mortality and a $56 \%$ patency rate. Five of these shunted patients had no further bleeding episodes and did not show encephalopathic impairment. Direct attack procedures - portoazygos operation (four patients) was associated with significant complications, including one fatality. Other direct approaches oesophageal transection and variceal plication (five patients) had variable outcome. Splenectomy alone (three patients) ameliorated hypersplenism; however, further surgery for recurrent haemorrhage (two patients) was necessary. Endoscopic sclerotherapy controlled recurrent variceal bleeding (three patients) when it became available to the unit. Conservative treatment practised in five children had little success: two patients survived, two died from further haemorrhage, and one was lost to follow up. These results suggest that in centres without endoscopic expertise, and for patients who are sclerotherapy 'failures', surgery can be performed safely and achieve reasonable long term success rates in childhood extrahepatic portal hypertension.

(Arch Dis Child 1994; 71: 437-440)
\end{abstract}

Portal hypertension is a predominant and potentially fatal cause of massive upper gastrointestinal haemorrhage in children. ${ }^{1-4}$ In this patient population extrahepatic venous obstruction secondary to portal vein thrombosis is a common finding. ${ }^{3-5}$ Despite improvements in understanding the natural history and pathophysiology of portal vein thrombosis, therapeutic strategies in managing extrahepatic portal hypertension in this subgroup of patients continues to remain controversial. ${ }^{36-18} \mathrm{~A}$ variety of surgical operations have been popularised, all with the aim of providing reasonable expectations for long term, good quality survival for the patients concerned. The cumulative morbidity and mortality experienced by different centres has, however, led many to caution expeditious surgical intervention. ${ }^{34} 15$ Furthermore, a concurrent revival of interest in endoscopic sclerotherapy led to new horizons in the overall management of patients with bleeding oesophageal varices. Thus endoscopic sclerotherapy is now increasingly offered as the treatment of choice to control bleeding oesophageal varices in many patients with complicated portal hypertension. ${ }^{14} 18-23$ Surgical intervention, as a consequence, has become designated to patients who continue to bleed after a course of sclerotherapy, for those who may have endoscopically inaccessible varices, and for the few patients with symptomatic splenomegaly. 1518

For a substantial proportion of paediatric patients, however, these latest options may not be readily available. Included in this category are patients for whom treatment focused primarily on surgically based techniques. ${ }^{19} 1324$ Moreover, there are those for whom a ready access to sophisticated health care facilities may continually be difficult (as in certain Third World communities) and mandates a uniform policy of surgical management. ${ }^{5172526}$ Data on the long term outlook for these children are conflicting. ${ }^{2}$ 5-7 912141617 25-27 We report here the cumulative surgical experience at our institution over a 20 year period in the management of childhood portal vein thrombosis and include long term follow up data that address the issues of future outcome and prognosis for this group of patients.

\section{Patients and methods}

Over a 20 year period (1960-80), 21 paediatric patients with portal vein thrombosis were diagnosed and treated at our institution. The series included 13 male and eight female patients (mean age 4.75 years; range seven months to 13 years). Diagnosis was established in these patients by percutaneous splenoportography. Oesophageal varices were confirmed on contrast barium swallow examination or by flexible upper gastrointestinal endoscopy after initial resuscitation and stabilisation of all patients. Liver biochemistry profiles were normal in all patients at initial presentation. Haemorrhage or splenomegaly were common modes of presentation. In nine patients $(43 \%)$ an identifiable precipitating event leading to thrombosis of the portal vein was recorded - seven patients had a definitive history of neonatal septicaemia, one developed a thrombosis after an exchange transfusion in the neonatal period for rhesus incompatibility, and the last patient had an associated congenital anomaly of the portal vein. Surgical intervention was planned when patients had one or more severe recurrent life threatening 
haemorrhagic episodes and did not respond to conservative management.

A policy of conservative management (volume resuscitation, pharmacological support, and balloon tamponade) was routinely used at our hospital for patients presenting with bleeding oesophageal varices. The study period under analysis covered a period when endoscopic sclerotherapy was regaining popularity; however, it was not uniformly practised in many centres, including our own unit. As a consequence, most patients presenting to us with recurrent life threatening haemorrhage, unresponsive to conservative treatment, had surgery performed expeditiously.

Criteria for portosystemic shunts were generally dictated by the presence of one or more patent veins demonstrable on splenoportal venography. Patients deemed 'unshuntable' (extensive venous thrombosis or aged less than 2 years with small diameter venous channels) underwent a variety of operations which were popular at that time. These included direct attack procedures - that is, oesophageal devascularisation and transection, Tanner portoazygos disconnection, variceal plication, and splenectomy. In some instances children were managed conservatively.

Children were reviewed at regular hospital and office visits by the attending paediatric surgeon, paediatrician, and general practitioner. Adult physicians and surgeons later assumed responsibility for health care once the child reached adolescence. Data were analysed from detailed reviews of the paediatric and adult hospital case records obtained through the medical record departments. All survivors (17 patients) were later contacted by telephone, postal service, or through their general

Patient management and outcome

\begin{tabular}{|c|c|c|c|}
\hline $\begin{array}{l}\text { Patient } \\
\text { No }\end{array}$ & $\operatorname{Sex}$ & $\begin{array}{l}\text { Operation details } \\
\text { (age at operation in years) }\end{array}$ & Current status (age in years) \\
\hline 1 & F & Central splenorenal shunt (13) & $\begin{array}{l}\text { Alive; blocked shunt no further } \\
\text { bleeds ( } 31 \text { ) }\end{array}$ \\
\hline 2 & $\mathbf{F}$ & Central splenorenal shunt (4) & $\begin{array}{l}\text { Alive; recurrent bleeds controlled } \\
\text { by sclerotherapy(23) }\end{array}$ \\
\hline 3 & $\mathbf{M}$ & Central splenorenal shunt (13) & Alive; no further bleeds (26) \\
\hline 4 & $\mathbf{M}$ & Central splenorenal shunt (7) & Alive; no further bleeds (29) \\
\hline 5 & $\mathbf{F}$ & Central splenorenal shunt (10) & Alive; no further bleeds (29) \\
\hline 6 & $\mathbf{F}$ & Central splenorenal shunt (8) & Alive; no further bleeds ( 31 ) \\
\hline 7 & $\mathbf{M}$ & $\begin{array}{l}\text { Central splenorenal shunt (13) } \\
\text { Oesophageal transection }(18)^{\star}\end{array}$ & $\begin{array}{l}\text { Alive; blocked shunt; recurrent } \\
\text { varices controlled by } \\
\text { sclerotherapy; no bleeds in } \\
\text { three years (31) }\end{array}$ \\
\hline 8 & $\mathbf{F}$ & $\begin{array}{l}\text { Central splenorenal shunt }(9) \\
\text { Plication of recurrent varices }(18)^{\star}\end{array}$ & $\begin{array}{l}\text { Alive; recurrent bleeds controlled } \\
\text { by sclerotherapy }(28)\end{array}$ \\
\hline 9 & $\mathbf{M}$ & $\begin{array}{l}\text { Portoazygos disconnection (1) } \\
\text { Mesocaval shunt (10) }\end{array}$ & Alive; no further bleeds (29) \\
\hline 10 & $\mathbf{M}$ & $\begin{array}{l}\text { Portoazygos disconnection (1) } \\
\text { Central splenorenal shunt (6) }\end{array}$ & $\begin{array}{l}\text { Alive; blocked shunt; } \\
\text { no further bleeds ( } 30)\end{array}$ \\
\hline 11 & $\mathbf{F}$ & $\begin{array}{l}\text { Portoazygos disconnection (1) } \\
\text { Oesophageal transection ( } 3 \text { ) }\end{array}$ & Alive; no further bleeds (28) \\
\hline \multirow[t]{2}{*}{$\begin{array}{l}12 \\
13 \\
14\end{array}$} & \multirow[t]{2}{*}{$\begin{array}{l}\mathbf{M} \\
\mathbf{M} \\
\mathbf{M}\end{array}$} & $\begin{array}{l}\text { Portoazygos disconnection (11 months) } \\
\text { Splenectomy (13) } \\
\text { Splenectomy (10 months) }\end{array}$ & $\begin{array}{l}\text { Died postoperative period } \\
\text { Alive; no further bleeds ( } 26)\end{array}$ \\
\hline & & $\begin{array}{l}\text { Oesophageal transection (1) } \\
\text { Plication of recurrent varices (1) }\end{array}$ & Alive; no further bleeds (22) \\
\hline 15 & $\mathbf{F}$ & $\begin{array}{l}\text { Splenectomy (2) } \\
\text { Mesocaval shunt }(11) \\
\text { Oesophageal transection }(15)^{\star} \\
\text { Plication of recurrent varices }(15)^{\star}\end{array}$ & $\begin{array}{l}\text { Alive; blocked shunt; } \\
\text { no further bleeds (27) }\end{array}$ \\
\hline $\begin{array}{l}16 \\
17 \\
18 \\
19\end{array}$ & $\begin{array}{l}\mathbf{M} \\
\mathbf{F} \\
\mathbf{F} \\
\mathbf{M}\end{array}$ & $\begin{array}{l}\text { Mesocaval shunt }(10)^{\star} \\
\text { Managed conservatively } \\
\text { Managed conservatively } \\
\text { Managed conservatively }\end{array}$ & $\begin{array}{l}\text { Alive; no further bleeds ( } 31 \text { ) } \\
\text { Alive; no further bleeds (22) } \\
\text { Alive; no further bleeds (27) } \\
\text { Died five years after diagnosis, } \\
\text { massive hematemesis }\end{array}$ \\
\hline 20 & $\mathbf{M}$ & Managed conservatively & $\begin{array}{l}\text { Died seven years after diagnosis, } \\
\text { massive hematemesis }\end{array}$ \\
\hline 21 & $\mathbf{M}$ & Managed conservatively & Lost to follow up \\
\hline
\end{tabular}

^Operation performed at another institution. practitioner and invited to attend for interview, clinical examination, and assessment of liver function. Shunt patency was determined by review of recent angiographic or Doppler duplex ultrasound studies. The mean duration of follow up in the study was 18 years (range 12-32 years).

\section{Results}

The table summarises patient management and outcome. Eight children (mean age 9.6 years) were treated primarily by central splenorenal shunting as popularised by Clatworthy and Boles in the late $1950 \mathrm{~s} .{ }^{28} \mathrm{All}$ of these patients are current long term survivors (mean age 28.5 years; range $23-31$ years). Five of these patients had no further bleeding episodes. The others required further intervention to control haemorrhage. In one of these patients recurrent varices were obliterated successfully by endoscopic sclerotherapy; the other two required oesophageal transection and variceal plication respectively and had a temporary relief in symptoms. Injection sclerotherapy was later performed in these patients to deal with further recurrent troublesome varices - both are now symptom free. Four patients within this group have maintained patent shunts.

Four patients had subcardiac portoazygos disconnection procedures. ${ }^{29}$ Additional surgical procedures were required in three of these children, all of whom are alive (mesocaval shunt in one, central splenorenal shunt in another, and oesophageal transection in the third) to control recurrent bleeding. The fourth child died in the early postoperative period as a result of a massive uncontrollable upper gastrointestinal haemorrhage.

Three children had splenectomy performed for hypersplenism refractory to medical management. Further surgery was undertaken in two of these patients to deal with the ongoing complications of portal hypertension. One child underwent an oesophageal transection and variceal plication just two months after his splenectomy; the other, remaining largely symptom free for nine years, underwent a mesocaval shunt which later thrombosed and necessitated an oesophageal transection and variceal plication to deal with recurrent variceal bleeding. These patients have had no further problems.

One child (now aged 31 years) had a mesocaval shunt performed primarily and has remained symptom free to date. Five patients were managed conservatively for technical reasons or because survival was anticipated. Two of these patients are alive and asymptomatic, two have died, five and seven years after diagnosis, and the last patient was lost to follow up.

Current survival in the study was $85 \%$ (mean patient age 27.6 years; range 22-31 years; mean period of follow up 18 years) and of these survivors, $88 \%$ have had variceal bleeds adequately controlled. Perioperative mortality in the series was $6 \%$. There were no intraoperative deaths. Six of 12 patients 
(50\%) have overall maintained patent shunts (four central splenorenal; two mesocaval). Liver biochemistry (total bilirubin, alkaline phosphatase, albumin, aspartate aminotransferase, alanine aminotransferase) and coagulation studies have remained within normal limits. Clinical examination, which included neurological evaluation, in the survivors (with and without portosystemic shunts) did not show evidence of encephalopathy and these patients continue to lead active, unrestricted lifestyles.

\section{Discussion}

The management of children with portal vein thrombosis has undergone many changes due to an improved understanding of the natural history and pathophysiology of this disorder. ${ }^{3-5} 8$ Injection sclerotherapy, first initially reported by Crafoord and Frenckner ${ }^{30}$ in the late 1930s, has re-emerged and established itself in many centres as the most effective therapeutic modality currently available to control variceal haemorrhage in patients who threaten to continue bleeding after a trial period of conservative management. ${ }^{14}{ }^{18-23}$ Despite these trends, however, surgery will remain important for the subset of patients who experience ongoing life threatening haemorrhage and for those in whom endoscopic facilities and expertise prove inaccessible or unavailable. ${ }^{5} 15-172526$ Data on the long term results of surgical intervention in such children with portal vein thrombosis remain an issue for continued debate. Concerns about the threats of portosystemic encephalopathy, shunt thrombosis, rebleeding, and sepsis after splenectomy dominate some of the issues which are addressed in this study. ${ }^{2-10} 12$ 14-17 2527

Portosystemic shunts were performed as primary procedures in nine patients in this series with a $56 \%$ success rate. At that time we had a preference for the central splenorenal shunt, which has remained patent in four of our patients. We seldom used the mesocaval shunt, but in the children (three patients) who underwent this procedure, two continue to maintain patency and do well. In our experience shunt surgery has served these patients well and can significantly reduce the incidence of rebleeding in patients with extrahepatic portal hypertension provided patency is maintained. These results were achieved without any mortality and follow up of this cohort has not shown any deterioration in liver function or clinical evidence to support encephalopathy. We believe encephalopathy is not a significant risk factor for the shunted child with portal vein thrombosis provided their liver function also remains normal. ${ }^{2-9} 12$ 14-17 25-27 31 These observations are, furthermore, supported by other institutions with larger patient series. ${ }^{1214161726}$

Direct surgical procedures such as portoazygos disconnection were associated with considerable morbidity and mortality in this small patient population. This operation is now rarely performed today for these reasons. ${ }^{13-58131532}$ Other direct procedures performed in this series, namely oesophageal transection and variceal plication, after a failed previous operation, gave reasonable results despite the reported high incidence of rebleeding cited by other workers. ${ }^{13-58131532}$

Splenectomy alone was associated with a poor outcome. 13-5815163233 Although achieving a temporary amelioration in symptoms in our patients with hypersplenism, further surgery was necessary in two children to deal with ongoing variceal bleeds. These patients have remained well, and have, as in other series, fortunately not yet experienced any sequelae. ${ }^{17}$

Conservative management was carried out exclusively in five children for technical reasons (extent of thrombosis making a conventional shunt unfeasible) or because of an anticipated favourable outcome. ${ }^{834}$ This proved to be the correct course of action to take in two children, who are currently alive, well, and free from haemorrhage. Predicting who is likely to benefit is fraught with error, as seen in the two other similarly managed children who died, whereas another patient was lost to follow up. Although some reports document a reduction in the frequency of bleeding episodes as the child gets older, conservative proponents must take into account the lethal risks of a subsequent variceal haemorrhage, which are currently estimated at $31 \%$ in Western societies. ${ }^{817}$ The current success rates reported with variceal endosclerosis may arguably make such a policy safer to adopt in technologically advanced societies provided that the facilities and expertise for endoscopic intervention are readily available. ${ }^{14} 18-23$ Makeshift shunts were not considered a realistic option for our patients who displayed extensive venous thrombosis. The poor results reported with these shunts influenced subsequent decision making for these patients. ${ }^{15}$

The overall results of this study encompass many of the changes that we have seen occur in the management of childhood extrahepatic portal hypertension over the last three decades. A policy of surgical management predominating in this series reflected the era in which the paediatric surgeon relied heavily on shunting or direct attack procedures to arrest recurrent life threatening variceal haemorrhage in the vulnerable child. Endoscopic sclerotherapy was extremely effective, when introduced into the study later, in controlling recurrent haemorrhage in our patients who thrombosed their shunts and in those who developed recurrent varices. Where endoscopic facilities and expertise exist, this should now undoubtedly represent the first approach to adopt when conservative treatment fails. In communities without these facilities and for children in whom sclerotherapy fails, our experience suggests that surgery, in selected hands, may be performed safely and be anticipated to achieve reasonable long term success rates.

1 Fonkalsrud EW. Surgical management of portal hypertension in childhood. Long-term results. Arch Surg 1980; 115: 1042-5.

2 Alman RP. Portal hypertension. In: Welch KJ, Randolph JG, Ravitch MM, O'Neill JA, Rowe MI, eds. Pediatric 1986: 1075-86. 
3 Fonkalsrud EW. Treatment of variceal haemorrhage in children. Surg Clin North Am 1990; 70: 475-87.

4 Karrer FM. Portal hypertension. Semin Pediatr Surg 1992 1: $134-44$.

5 Cohen J, Edelman RR, Chopra S. Portal vein thrombosis: a review. Am ₹ Med 1992; 92: 173-82.

6 Voorhees AB, Chaitmann E, Schneider S, et al. Portalsystemic encephalopathy in the non-cirrhotic patient. Effect of portal-systemic shunting. Arch Surg 1973; 107: 659-62.

7 Grauer SA, Schwartz SI. Extrahepatic portal hypertension: a retrospective analysis. Ann Surg 1978; 189: 566-74.

$8 \mathrm{Webb}$ LJ, Sherlock S. The aetiology, presentation and natural history of extra-hepatic portal venous obstruction $Q \mathcal{F}$ Med 1979; 192: 627-39.

9 Alvarez F, Bernard O, Brunelle F, et al. Portal obstruction in children. II. Results of surgical portosystemic shunts. $f$ Pediatr 1983; 103: 703-7.

10 Spence RAJ, Johnston GW, Odling-Smee GW, Rodgers HW. Bleeding oesophageal varices with long term follow up. Arch Dis Child 1984; 59: 336-40.

11 Stellen GP, Lilly JR. Esophageal endosclerosis in children. Surgery 1985; 98: 970-4

12 Alagille D, Carlier JC, Chiva M, et al. Long-term neuropsychological outcome in children undergoing portalsystemic shunts for portal vein obstruction without live disease. F Pediatr Gastroenterol Nutr 1986; 5: 861-6.

13 Belli L, Romani F, Rioli F, et al. Thrombosis of portal vein in absence of hepatic disease. Surg Gynecol Obstet 1989; 169: 46-9.

14 Maksoud JB, Pecanha Goncalves ME, Porta G, et al. The endoscopic and surgical management of portal hypertension in children: analysis of 123 cases. $\mathcal{f}$ Pediatr Surg 1991; 26: 178-81.

15 Heaton ND, Howard ER. Surgical intervention in children with portal hypertension. Pediatr Surg Int 1993; 8: 306-9.

16 Orloff MJ, Orloff MS, Rambotti M. Treatment of bleeding esophagogastric varices due to extrahepatic portal hyperesophagogastric varices due to extrahepatic portal hypertension: results of portal-systemic

17 Prasad AS, Gupta S, Kohli V, Pande GK, Sahni P, Nundy S. Proximal splenorenal shunts for extrahepatic portal venous obstruction in children. Ann Surg 1994; 219: $193-6$.

18 Stringer MD, Howard ER. Longterm outcome after injection sclerotherapy for oesophageal varices in children with extrahepatic portal hypertension. Gut 1994; 35: 257-9.

19 Johnston GW, Rodgers HW. A review of 15 years experience in the use of sclerotherapy in the control of acute haemorrhage from oesophageal varices. $\mathrm{Br} \mathcal{F}$ Surg 1973; 60: 797-800.

20 Terblanche J, Northover JMA, Bornmann PC, et al. A prospective evaluation of injection sclerotherapy in the treatment of acute bleeding from oesophageal varices. Surgery 1979; 85: 239-45.

21 Lilly JR, Van Stiegman G, Stellin G. Esophageal endosclerosis in children with portal vein thrombosis. $f$ Pediatr Surg 1982; 17: 571-5.

22 Howard ER, Stamakis JD, Mowat AP Management of esophageal varices in children by injection sclerotherapy. 7 Pediatr Surg 1984; 19: 2-5.

23 Howard ER, Stringer MD, Mowat A. Assessment of injection sclerotherapy in the management of 152 children with oesophageal varices. $B r \mathcal{F}$ Surg 1988; 75: 404-8.

24 O'Donnell B, Moloney MA. Development and course of extrahepatic portal obstruction in children. Lancet 1968; i 789-91.

25 Mohapatra MK, Mohapatra AK, Acharya SK, et al. Encephalopathy in patients with extrahepatic obstruction after lienorenal shunts. Br F Surg 1992; 79: 1103-5.

26 Mitra SK, Rao KLN, Narasimhan KL, et al. Side-to-side lienorenal shunt without splenectomy in noncirrhotic portal hypertension in children. $f$ Pediatr Surg 1993; 28: tal hyperten.

27 Hassall E, Benson L, Hart M, et al. Hepatic encephalopathy after portocaval shunt in a non cirrhotic child. $\mathcal{F}$ Pediat 1984; 105: 439-41.

28 Clatworthy HW, Boles ET. Extrahepatic portal bed block in children: pathogenesis and treatment. Ann Surg 1959, 150: 371 .

29 Tanner NC. The late results of porto-azygos disconnection in the treatment of bleeding from Ann R Coll Surg Engl 1961; 28: 153-74.

30 Crafoord C, Frenckner P. New surgical treatment of varicose veins of the oesophagus. Acta Otolaryngol (Scand) 1939; 27: 422 .

31 Thomas PG, D'Cruz AJ. Distal splenorenal shunting for bleeding gastric varices. Br ₹ Surg 1994; 81: 241-4.

32 Boles ET, Wise WE, Birken G. Extrahepatic portal hypertension in children. Long term evaluation. Am $\mathcal{f}$ Surg 1986; 151: 734-9.

33 MacPherson AIS. Portal hypertension due to extrahepatic portal venous obstruction. A review of 40 cases. $\mathcal{f} R$ Coll Surg Edinb 1984; 29: 4-10.

34 Fonkalsrud EW, Myers NA, Robinson MJ. Management of extrahepatic portal hypertension in children. Ann Surg 1974; 180: 487-91. 